\title{
A Study on the Application of Creative Painting in Yiwu City 's Cultural Construction--Case of landscaping
}

\author{
Ping Jin \\ Yiwu Industrial and Commercial College, Yiwu Zhejiang, 322000, China
}

Key words: Creative painting, Yiwu, Urban culture, Construction, Application.

\begin{abstract}
Creative painting has distinct characteristics of individuality, the interactive characteristics of civic participation and the characteristics of civilians, which can fully meet the current aesthetic of the public and meet the needs of Yiwu urban culture construction. Creative painting in Yiwu city construction process, should pay attention to the application of creative painting principles, to improve the city of Yiwu personalized face, to enhance the artistic taste of Yiwu city culture, which Yiwu city culture has a positive effect. This paper analyzes the application of creative painting in Yiwu city construction.
\end{abstract}

\section{Introduction}

In Yiwu city culture construction, the current cultural elements into the city construction, with creative painting of the aesthetic, image and subjectivity, so that in Yiwu city culture plays an important role. At present, Yiwu city cultural construction has entered the era of urban aesthetics, whether from the creative motivation, the production process or works, creative painting can give the audience a passionate visual impact, creative painting in various forms, and very aesthetic, Can be dull, monotonous Yiwu city building play a good regulatory role, to live in Yiwu people bring surprises and joy. Yiwu City, the number of cable boxes, a serious impact on the city of Yiwu City, the use of creative painting on the box packaging and landscaping, Yiwu City, the external public environment and the internal living environment for effective improvement and packaging, and Compared with other types of art forms, creative painting has a unique advantage, more suitable for the construction of Yiwu city culture, and Yiwu city culture plays a positive role in promoting.

\section{An Overview of Creative Painting and Its Application in Yiwu 's Urban Cultural Construction}

Creative painting is a distinctive and distinctive art form. At this stage in the stage of rapid development of the city, most of the busy life and work, there is not much leisure time to take the initiative to pay attention to art, although able to take some time to the museum, but most can not fully understand the ivory tower of high-end art, Visible, living in Yiwu people want to cultivate their art through art, to improve their aesthetic ability is already a luxury. Yiwu urban cultural construction urgently needs a kind of easy to understand art form, cultivate people's sentiment, improve people's artistic aesthetic ability, and into the public life to guide the public aesthetic, fully meet the public's aesthetic needs.

Personality is characterized by creative painting of the artistic characteristics of the birth, from the creative painting when it has a maverick pursuit. Creative creators are based on the individual's view of social works of art creation, and creative painting in the creation, do not accept any art form of the shackles, the author in the creation of the usual selection of different materials and hue and creative techniques, In order to highlight their own value. Yiwu city culture in the creation of cartoon characters, landscapes, graphics and other creative painting works, are the pursuit of individual 
freedom of the performance of the artist, and strive to create different works of art and others, the formation of creative painting works with personality.

Yiwu city culture construction in the creative painting with civilians, the characteristics of public participation and interaction. Most of the creators of creative painting have good creative ideas, mastered the techniques and techniques of painting, and can interpret social phenomena or express their thoughts and feelings from different angles. Creative painting is a common content in the daily life of Yiwu people. Creative painting works with intuitive and clear features. Different creative works can infect different audiences. There are no elegant and decentralized paintings. Most of them are civilians and popular. Civilians' thought of material performance art. Creative painting in Yiwu city has many corners, this creative painting works to give the audience the feeling of immersive, the audience can interact with the work, so that art and the audience have a certain relationship for the audience to bring a warm feeling The In the creation of Yiwu city's creative painting, we used the image of squirrel and nut in the glacier era 5 (Figure 1), which made the friends who love the film resonate and make the urban creative painting keep up with the trend of the times. Yiwu city culture construction in the creative painting works effect is obvious, decorative strong, the use of a large number of high purity, hue bright colors. Strong colors and simple styling, can bring a strong visual impact, emphasizing the entertainment, symbolic and childlike creative painting has a strong decorative. Yiwu urban culture in the creative painting in the creation of more selection of the theme of daily, it is easy to be accepted by the public. Creative painting selected themes are more common people in life, things, things, to fully express the public's thoughts and feelings. We use the film "crazy animal city" inside the fox Nick and rabbit Judy two cartoon image painting works (Figure 2), the two favorite friends by the audience role in people's lives, for people Of life add luster, bring vitality and fun. Creative painting also has the characteristics of rapid construction and low construction cost. The creator of the artwork can complete the creation of the work in a short time. The creative staff only needs to be responsible for the creation of his own works, less personnel and reduce the cost of creation The.

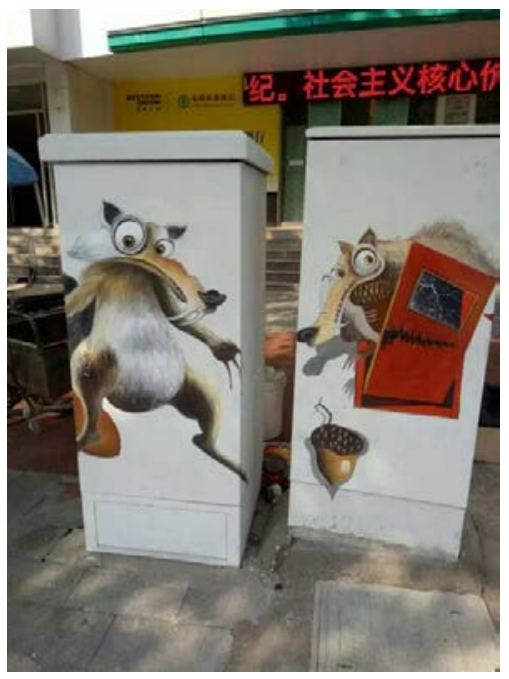

Fig. 1

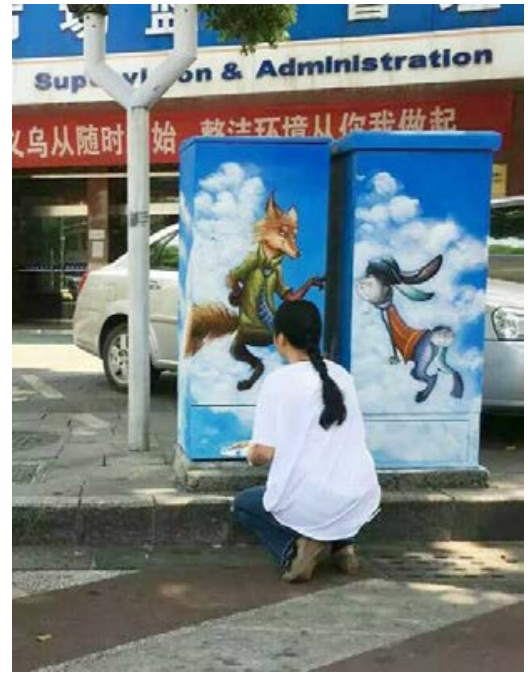

Fig. 2

\section{The Application Principle of Creative Painting in Yiwu Urban Culture Construction Overall coordination principle}

Creative painting in Yiwu city culture construction application, should follow the overall coordination principle, to avoid creative painting works color uncoordinated, or too different, not only can not bring beauty to the city, but also to the city to build a few more "psoriasis" The In the construction of urban culture, according to the need to choose the best creative painting works, so that works follow the principle of overall coordination for the city of Yiwu city culture add luster. 


\section{The principle of artistic strong}

Creative painting at this stage is a more popular form of artistic expression, creative painting works should be able to withstand the art form of the United States and the law of careful scrutiny of the work of the primary and secondary, the actual situation and color contrast should be coordinated, local details should be consistent with the overall effect. Through this, we should have a comprehensive idea of creative painting works, choose the best creative materials and advanced drawing technology, effectively improve the art of the work, gives a strong artistic experience, so that the art content of the work higher, follow the artistic Strong principles, so that works more expressive.

\section{Regional cultural principles}

Yiwu city culture construction in the application of creative painting must follow the principle of regional culture, the art rooted in the Yiwu culture soil, in order to make it more vitality, will receive the majority of the people's favorite. In the process of creative creative painting, the creator will excavate and carry forward the cultural characteristics of Yiwu city, and effectively activate the cultural and artistic creativity of Yiwu people from the aspects of history, nature and human factors, and lay a solid foundation for Yiwu city to become characteristic city Foundation.

\section{The Application of Creative Painting in Yiwu City 's Cultural Construction}

\section{Improve the Yiwu city personalized face}

Yiwu city cultural construction of the individuality of the construction of Yiwu City is the main content of creative painting in Yiwu city culture construction application to effectively improve the Yiwu city personalized face, embodies the artistic value of the existence of the city. Yiwu City, there are some historical monuments, cultural legacy and characteristics of customs, which Yiwu city's personalized face to create a positive role in promoting. Yiwu city personalized face can also be from the city "flexible packaging" point of view, in the pursuit of Yiwu building height and architectural style on the basis of personalized, high-quality cultural and artistic atmosphere of the individual pursuit. We use the creative painting of the cable box in Yiwu made a creative design, in the cable box to draw the pattern of grasping the baby machine (Figure 3), so that the cable box is no longer give people a cold and serious feeling for people to bring relaxed and happy Visual enjoyment. Yiwu city construction planning color theory shows: Yiwu city color can intuitively reflect the Yiwu city personalized characteristics. Color can give people a great impact on life, and the impact is higher than the color attached to the image and carrier. In the current Yiwu city culture construction, people often overlooked the diverse needs of the building environment. Yiwu city culture construction and modern personality must be publicity, the pursuit of freedom, the pursuit of a better concept of life to adapt. In the cable box to draw a simple moving material (Figure 4: the theme of the movement of the draft), can play a certain beneficial impact on people, enhance people's awareness of sports and fitness, and thus improve the spirit of the city's style.

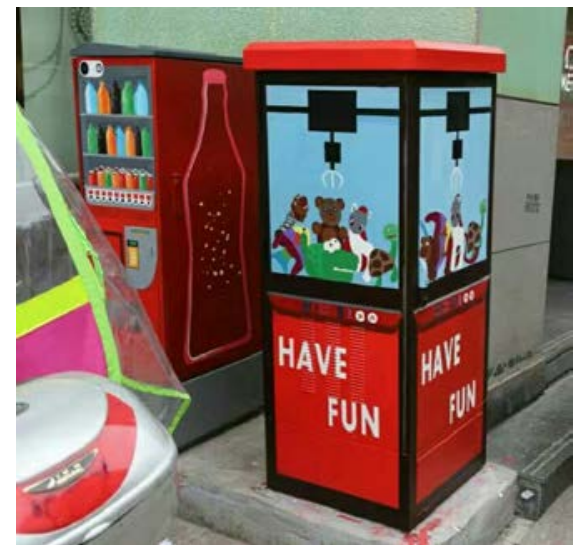

Fig. 3
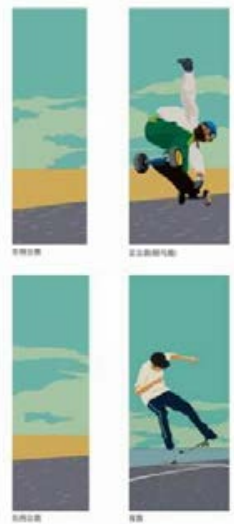

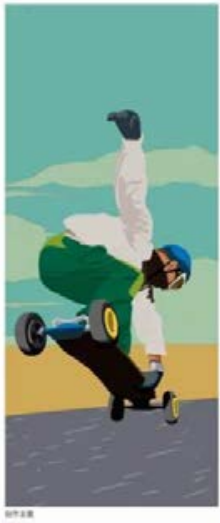

Fig. 4 


\section{Enhance the artistic and cultural taste of Yiwu City}

As we all know, artistic taste is a comprehensive view of human life, aesthetics and values. People only have a good outlook on life, aesthetics and values, in order to have a noble taste. In Yiwu city culture construction and urban development, cultural orientation and artistic orientation of Yiwu city art atmosphere to create a great role in promoting, Yiwu public aesthetic value of the guide intuitive reflects the cultural taste of Yiwu. At this stage, Yiwu city culture construction only emphasizes the function of the building, which can only meet people's basic material level demand. A serious lack of self-willed multi-dimensional care, ignoring the aesthetic pursuit of people. Creative painting development to today, has become an important form of art, in modern life, creative painting on people's lives have a great impact, mainly because the creative painting has a certain cultural and artistic connotation. Creative painting and gallery in the elegant art works have a certain difference, creative painting of the origin of its decision to civilians, grassroots of the artistic properties, creative art of painting to make it a high cultural taste. Yiwu city culture in the creative painting of the beautiful shape, beautiful colors and creative ideas is creative painting high-grade direct performance, creative painting with artistic elements necessary aesthetic elements, reflecting the creative painting of the universal aesthetic. Creative painting works of art creative motives let it has a maverick personality charm, fully embodies the creative painting of the aesthetic aesthetic characteristics. In Yiwu City Square, public cultural space, public landscape into the creative painting, make people in Yiwu City, the United States to enjoy the beauty, and fully meet people's aesthetic needs. Creative painting this popular art, you can let Yiwu everyone can feel, taste to the arts, so as to effectively enhance the city of Yiwu city art and cultural taste.

\section{Beautify the urban living environment of Yiwu City}

Creative painting can play a beautification of Yiwu city environment, add the role of urban vitality, especially in Yiwu City into a transformation process, creative painting can give full play to their role. The application of creative painting to Yiwu city culture construction can make creative painting rise to public art form, construct Yiwu city public space characteristics, enhance Yiwu city public space quality. Creative painting can also make up the Yiwu city public space homogenization of the defects, Yiwu city space and art effectively linked to play a role in mining and guide the city culture. Will be creative painting into the city of Yiwu city culture construction, can fully meet people's aesthetic needs, so that people through the art of catharsis suppressed instincts, so that in the creative painting art to get emotional sustenance. Creative painting can play a role in beautifying the urban environment, people in the process of appreciation of the creation of painting works can produce a pleasant psychological feeling, we can see, creative painting in Yiwu City, the construction of urban culture, the formation of people's health psychology To greatly promote the role. In Yiwu city culture construction application of creative painting, can play a positive role in promoting the transformation of the old city. Creative painting Yiwu City, the construction of the defects have a certain coverage and repair role, Yiwu creative painting works in the decoration, become colorful, creative full. Good creative painting can bring people a new visual experience, people enjoy the creative painting works, often overlooked urban buildings in the tattered side, creative painting can make the old city show vitality. Creators in the creation of creative painting works, usually choose the people loved the theme, these works can make the old city a new look, to achieve the creative painting art and Yiwu culture of the organic combination of enhanced Yiwu City, the beauty of the old city, effective Beautify the urban living environment of Yiwu City.

\section{Summary}

As the creative painting with decorative features, to a large extent to improve the appearance of Yiwu City, it played a very good role in beautification. The cultural attributes and aesthetic attributes of creative painting have effectively promoted the aesthetic level of the public and enhanced the inner cultural and artistic taste of Yiwu city. The application of creative painting to Yiwu city culture 
construction, must be organized and guided by the Yiwu municipal government departments, creative painting and environmental benign development together, in order to make creative painting bloom glory, and better promote the construction of Yiwu city culture.

\section{Acknowledgement}

This paper is one of series results of 2016 Zhejiang Province Department of Education project support, Zhejiang Province, $13^{\text {th }}$ Five Year Plan advantage construction professional product art design.

\section{References}

[1] Fan Xihong. On the urban public cultural facilities in the development of urban culture in the positioning, Inner Mongolia Art, 2016 (02).

[2] Ren Qingguo. Urban planning from the perspective of the study of urban culture construction rating, Heilongjiang Science and Technology Information, 2017 (02).

[3] Yu Changhai. Chongqing city culture construction problems and countermeasures, Culture and Education (on), 2014 (02).

[4] Li Han, Wang Yunqing. Luoyang City as an example to talk about cultural heritage protection and urban cultural construction, Theoretical observation, 2014 (05).

[5] Zhou Xueqin. Contemporary China's urban culture construction path analysis, Jiaozuo University, 2013 (02). 